\title{
Flora da Usina São José, Igarassu, Pernambuco: Myrtaceae
}

\author{
Flora of Usina São José, Igarassu, Pernambuco: Myrtaceae
}

\author{
Bruno Sampaio Amorim ${ }^{1,2}$ \& Marccus Alves ${ }^{1}$
}

\begin{abstract}
Resumo
Myrtaceae é representada no Brasil por 928 espécies e tem a Floresta Atlântica como um de seus centros de diversidade, apresentando 636 espécies, das quais 77,5\% são endêmicas. Neste estudo foram tratadas as 23 espécies da família encontradas em fragmentos de Floresta Atlântica de Terras Baixas na Usina São José ao norte do estado de Pernambuco. Eugenia é o gênero mais representativo com dez espécies (E. candolleana, E. dichroma, E. excelsa, E. florida, E. hirta, E. aff. prasina, E. punicifolia, E. umbelliflora, E. umbrosa, E. uniflora), seguido de Myrcia com oito espécies (M. bergiana, M. guianensis, M. racemosa, M. spectabilis, $M$. splendens, M. sylvatica, M. tomentosa, M. verrucosa), Psidium com duas espécies ( $P$. guajava e $P$. guineense) e Calyptranthes, Campomanesia, e Myrciaria com uma espécie cada (Calyptranthes dardanoi; Campomanesia dichotoma; M. ferruginea). São apresentados chave de identificação e comentários sobre as espécies, além de ilustrações dos caracteres diagnósticos.
\end{abstract}

Palavras chave: taxonomia, florística, terras baixas, Neotrópicos, Brasil.

\begin{abstract}
Myrtaceae comprises 928 species in Brazil. The Atlantic Rain Forest is a center of diversity of the family with 636 species and 77,5\% of them are endemic. This study presents 23 species of Myrtaceae which were found at Usina São José in fragments of Lowland Atlantic Rain Forest of northern Pernambuco. Eugenia is the richest genus with ten species (E. candolleana, E. dichroma, E. excelsa, E. florida, E. hirta, E. aff. prasina E. punicifolia, E. umbeliflora, E, umbrosa, and E. uniflora), followed by Myrcia with eigth species (M. bergiana, M. guianensis, M. racemosa, M. spectabilis, M. splendens, M. sylvatica, M. tomentosa, and M. verrucosa); Psidium with two species (P. guajava and P. guineense) and Calyptranthes, Campomanesia and Myrciaria with one specie each (Calyptranthes dardanoi, Campomanesia dichotoma, and M. ferruginea). Identification keys, descriptions, comments and illustrations of the species are presented.
\end{abstract}

Key words: taxonomy, floristics, endemic, Neotropics, Brazil.

\section{Introdução}

Myrtaceae apresenta distribuição pantropical, onde Austrália, sudeste asiático e América tropical são centros de diversidade, e compreende 133 gêneros e próximo de 3800 espécies (Wilson et al. 2001), dos quais 30 gêneros e cerca de 2300 espécies (Govaerts et al. 2010) pretencem à tribo Myrteae (sensu McVaugh 1968). No Brasil, Myrtaceae é representada por 927 espécies, sendo 707 endêmicas do país (Sobral et al. 2010). O domínio da Floresta Atlântica é um dos centros de diversidade da família, a qual é a sexta mais representativa (Stehmann et al. 2009) com636 espécies, sendo 77,5\% endêmicas (Sobral et al. 2009).
Os gêneros mais representativos são Eugenia e Myrcia, apresentando de 600 e 350 (sensu Stehmann et al. 2009) a 1070 e 394 (sensu Govaerts et al. 2010) espécies respectivamente, das quais 241 e 132 espécies ocorrem no domínio Atlântico (Stehmann et al. 2009).

Para o Brasil, existem 55 espécies nas listas vermelhas da Biodiversitas, IUCN e MMA (Sobral et al. 2009) sendo a exploração madeireira o principal fator de risco para seu desaparecimento. Apesar dos diversos estudos taxonômicos disponíveis, a maioria deles está concentrada nas Regiões Sudeste (Arantes \& Monteiro 2002; Souza et al. 2007; Souza \& Morim 2008) e Sul (Legrand \& Klein 1967-1978; Sobral 2003;

\footnotetext{
${ }^{1}$ Universidade Federal de Pernambuco, Depto. Botânica, Av. Prof. Moraes Rego 1235, Cidade Universitária, 50670-901, Recife, PE, Brasil.

${ }^{2}$ Autor para correspondência: brunosarim@yahoo.com.br
} 
Romagnolo \& Souza 2006). No Nordeste os estudos taxonômicos ainda são escassos (Barros 2005; Silva 2009; Lourenço 2010). Neste estudo foram tratadas 23 espécies da família encontradas em fragmentos de Floresta Atlântica de Terras Baixas na Usina São José ao norte do estado de Pernambuco.

\section{Material e Métodos}

A Usina São José (USJ) localiza-se na Zona da Mata Norte, a $28 \mathrm{~km}$ de Recife, no município de Igarassu - Pernambuco (7040'21,25'-7055' 50,92'S e $34^{\circ} 54^{\prime} 14,25^{\prime \prime}-35^{\circ} 05$ '21,08'W) (Trindade et al.2008). Possui uma área total de $280 \mathrm{~km}^{2}$ e cerca de 100 fragmentos florestais com diferentes áreas e formatos. Para a classificação dos habitats nos fragmentos estudados, foi adotado Silva et al. (2008). As coletas foram realizadas durante o período de 2008-2011 e concentraram-se em seis fragmentos selecionados com área entre $30-400 \mathrm{~m}^{2}$. As amostras botânicas foram submetidas às técnicas usuais em taxonomia vegetal (Mori et al. 1985) e depositadas no herbário UFP, com duplicatas distribuídas aos herbários MO, NY, RB e SP. Adicionalmente, foram incluídas informações obtidas a partir das coleções depositadas nos herbários ALCB, ASE, HST, HUEFS, IPA, JPB, MAC, MO, NY, PEUFR, PH, RB, SP, SPF, UFRN e UFP (acrônimos segundo Thiers 2010).

As identificações foram realizadas com o auxílio de bibliografia especializada (McVaugh 1969; Landrum 1986; Sobral 1993; Soares-Silva 2000) e por comparação com amostras previamente identificadas por especialistas, incluindo tipos. A caracterização das inflorescências, tipologia dos frutos e morfologia foliar seguiram McVaugh (1956), Spjut (1994) e Hickey (1973), respectivamente.

A estrutura dos resultados abaixo apresentados segue as monografias previamente publicadas para a área de estudo (Alves-Araújo \& Alves 2010; Melo et al. 2010; Pontes \& Alves 2010; Buril \& Alves 2011).

\section{Resultados e Discussão}

Na USJ, Myrtaceae está entre as famílias com maior diversidade taxonômica, com 23 espécies (Alves-Araújo et al. 2008). Destas, Eugenia é o gênero mais representativo, com dez espécies, seguido de Myrcia com oito, Psidium com duas e Calyptranthes, Campomanesia e Myrciaria com uma espécie cada. A família é composta por espécies endêmicas da Floresta Atlântica (próximo de 50\%) e espécies que apresentam ampla distribuição na América do Sul. Eugenia e Myrcia apresentam o maior número de espécies endêmicas (quatro espécies cada), seguido de Calyptranthes, Campomanesia e Myrciaria com uma espécie cada. Myrcia verrucosa, considerada até então restrita para o estado do Espírito Santo (Sobral 2006; Sobral et al. 2010) é registrada pela primeira vez para a Floresta Atlântica nordestina.

\section{Tratamento taxonômico}

Myrtaceae Juss.

Árvores, arvoretas ou arbustos; ramos jovens pilosos, tronco em geral com córtex esfoliante. Folhas opostas, simples, broquidódromas, pontuações translúcidas presentes; estípulas ausentes. Inflorescência tipo panícula, racemo, dicásio ou flores solitárias; flores bissexuadas, actinomorfas, diclamídeas, cálice 4-5-lobado ou caliptriforme, corola 4-5-mera; hipanto prolongado ou não acima do ovário; androceu polistêmone; estigma capitado; ovário ínfero. Frutos baga. Semente 1 a numerosas, coloração uniforme ou maculada, lisa ou muricada.

\section{Chave para identificação das espécies de Myrtaceae na USJ}

1. Inflorescência tipo panícula

2. Folhas com venação primária sulcada adaxialmente

3. Folhas ovadas, pecíolo ca. $1 \mathrm{~mm}$ compr.; lobos do cálice com ápice rotundo; frutos elipsoides 18. Myrcia sylvatica

3'. Folhas elípticas a obovadas, pecíolo $>3 \mathrm{~mm}$ compr.; lobos do cálice com ápice agudo ou cálice caliptriforme com opérculo apiculado; frutos globoides a subgloboides.

4. Folhas $4-8 \mathrm{~cm}$ compr.

5. Cálice com lobos de comprimento desigual, 4 maiores com $2 \mathrm{~mm}$ compr., 1 menor com $1 \mathrm{~mm}$ compr., ápice agudo; frutos lisos; semente de coloração uniforme 
5. Cálice com lobos de comprimento igual, ápice falciforme; frutos verrucosos; semente maculada

4. Folhas 11-15 cm compr.

6. Cálice caliptriforme, calíptra apiculada; disco estaminal glabro; estilete glabro

1. Calyptranthes dardanoi

6. Cálice não caliptriforme, lobos imbricados, ápice rotundo; disco estaminal piloso; estilete com base pilosa

16. Myrcia spectabilis

2'. Folhas com venação primária plana a saliente adaxialmente.

7. Tricomas ferrugíneos

13. Myrcia bergiana

7'. Tricomas não ferrugíneos.

8. Cálice com lobos de comprimento desigual, 3 maiores com $2 \mathrm{~mm}$ compr., 2 menores com 1 mm compr.; ovário 3-locular 14. Myrcia guianensis

8'. Cálice com lobos de comprimento igual; ovário 2-locular.

9. Lobos do cálice com ápice rotundo; disco estaminal piloso; estilete com base pilosa; frutos elipsoides 17. Myrcia splendens

9'. Lobos do cálice com ápice agudo; disco estaminal glabro; estilete glabro; frutos globoides 15. Myrcia racemosa

1'. Inflorescência tipo racemo (eixo primário desenvolvido ou reduzido), dicásio ou flor solitária.

10. Inflorescência com eixo primário desenvolvido ou reduzido.

11. Inflorescência com eixo primário desenvolvido, $\leq 1 \mathrm{~cm}$ compr.

12. Eixo primário da inflorescência de 1,5-2,5 cm compr.; bractéolas lanceoladas; disco estaminal piloso; estilete com base pilosa 3. Eugenia candolleana

12'. Eixo primário da inflorescência de 2,6-4,5cm compr.; bractéolas rotundas; disco estaminal glabro; estilete glabro

6. Eugenia florida

11'. Inflorescência com eixo primário reduzido, $\geq 0,1 \mathrm{~cm}$ compr.

13. Hipanto prolongado acima do ovário; frutos com lobos do cálice decíduo

21. Myrciaria ferruginea

13’. Hipanto não prolongado acima do ovário; frutos com lobos do cálice persistente.

14. Inflorescência com ramificação de apenas dois eixos secundários; brácteas-2; bractéolas rotundas

14'. Inflorescência com ramificação de mais de dois eixos secundários; brácteas-2 ou mais; bractéolas elípticas ou lanceoladas.

15. Venação secundária 4-7 pares.

16. Inflorescência com eixo secundário 15-20 mm compr.; ovário 8-costado; disco estaminal piloso; frutos 8-costados 12. Eugenia uniflora

16'. Inflorescência com eixo secundário 2-7 mm compr.; cálice não segmentado; disco estaminal glabro; frutos não costados 7. Eugenia hirta

15'. Venação secundária 8 ou mais pares.

17. Folhas com venação secundária 14-16 pares; disco estaminal piloso ....

4. Eugenia dichroma

17'. Folhas com venação secundária 8-12 pares; disco estaminal glabro.

18. Folhas com venação marginal até $2 \mathrm{~mm}$ da borda; bractéolas lineares

19. Folhas até $5 \mathrm{~cm}$ larg.; eixo secundário da inflorescência $10 \mathrm{~mm}$ compr.; brácteas elípticas; frutos globoides, lisos; semente globoide, coloração uniforme 5. Eugenia excelsa

19'. Folhas 5,5-6,5 cm larg..; eixo secundário da inflorescência $1 \mathrm{~cm}$ compr.; brácteas lanceoladas; frutos elipsoides, rugosos; semente elipsoide, maculada

8. Eugenia aff. prasina

18'. Folhas com venação marginal $3-4 \mathrm{~mm}$ da borda; bractéolas lanceoladas a discóide-lanceoladas.

20. Folhas 5-9,5 cm compr., venação secundária 8 pares; pecíolo $4 \mathrm{~mm}$ compr.; frutos subgloboides, lisos; semente imaculada ..

10. Eugenia umbelliflora 
20'. Folhas 10,5-27 cm compr., venação secundária 10-12 pares; pecíolo 8-11 mm compr.; frutos elipsoides, verrucosos; semente maculada 11. Eugenia umbrosa

10'. Inflorescência tipo dicásio ou flores solitárias.

21. Folhas com venação secundária de 10-15 pares; flores solitárias 22. Psidium guajava

21'. Folhas com venação secundária de 6-8 pares; flores solitárias e/ou dispostas em dicásio.

22. Flores solitárias e/ou inflorescência tipo dicásio; botão floral constricto entre o ovário e o globo petalífero; disco estaminal glabro; ovário 6-locular; frutos não constrictos; sementes lisas

23. Psidium guineense

22'. Inflorescência tipo dicásio; botão floral não constricto; disco estaminal piloso; ovário 8-10locular frutos constrictos apicalmente; sementes muricadas .

2. Campomanesia dichotoma

Calyptranthes Sw., Prodr. 5: 79. 1788.

Arvoretas ou arbustos, ramificações dicotômicas. Inflorescência tipo panícula, brácteas em geral decíduas, bractéolas persistentes; cálice caliptriforme, abertura regular, calíptra apiculada; hipanto prolongado acima do ovário; estames aderidos à margem apical do cálice; ovário 2-locular. Frutos globoides, cálice persistente. Semente ssubgloboide, coloração uniforme.

Gênero com 250 espécies, 42 delas ocorrem na Floresta Atlântica, sendo 24 endêmicas (Sobral et al. 2009).

1. Calyptranthes dardanoi Mattos, Loefgrenia 99: 1.1990.

Fig. 1a-c

Arvoretas a arbustos ca. 3-5 m alt., ramos jovens pilosos, tricomas ferrugíneos. Folhas 11,5$15 \times 4,6-6 \mathrm{~cm}$, cartáceas, elípticas, acuminadas, atenuadas; venação primária sulcada adaxialmente, secundária 16-18 pares, marginal a $2 \mathrm{~mm}$ da borda foliar; pecíolo $6-10 \mathrm{~mm}$ compr., piloso. Inflorescência panícula, pilosa, tricomas ferrugíneos, eixo primário ca. 8,5 cm compr., ramificação até terceira ordem; brácteas $3 \mathrm{~mm}$ compr., lanceoladas, pilosas; bractéolas $1 \mathrm{~mm}$ compr., lineares, pilosas; cálice caliptriforme $3 \mathrm{~mm}$ compr., piloso; calíptra $1 \mathrm{~mm}$ compr., apiculada, pilosa; hipanto prolongado, $2 \mathrm{~mm}$ compr.; estames $4 \mathrm{~mm}$ compr., aderido à margem superior do cálice, disco estaminal glabro; estilete $8 \mathrm{~mm}$ compr., glabro. Frutos $0,6 \times 0,6 \mathrm{~cm}$, globoides, cálice persistente, glabro. Semente 1, 0,5 $\times 0,4 \mathrm{~cm}$, subgloboide, lisa, coloração uniforme.

Material examinado: Mata de Piedade, 20.II.2009, fl., B.S. Amorim 389a et al. (UFP); 15.IX.2009, fr., J.D. Garcia 1173 et al. (UFP); 29.I.2010, fl., B.S. Amorim 558 et al. (UFP). Material adicional: BRASIL. PERNAMBUCO: Goiana, 28.XII.1965, fl., A. Lima 65-4346 (IPA).
Endêmica daFloresta Atlântica (Sobral et al. 2009) e conhecida apenas para o estado de Pernambuco (Govaerts et al. 2010; Sobral et al 2010). Na USJ é uma espécie rara e ocorre no interior dos fragmentos, em habitats de terraço e sítio ripário. Diferencia-se por apresentar ramificações dicotômicas e cálice caliptriforme, com abertura regular e persistente no fruto.

Campomanesia Ruiz \& Pav., Fl. peruv. prodr.: 72. 1794. Arvoretas ou arbustos. Inflorescência tipo dicásio simples; cálice 5-mero, corola 5-mera; hipanto prolongado acima do ovário; ovário 8-10 locular. Frutos globoides, cálice persistente. Sementes reniformes, coloração uniforme, muricadas.

Gênero com 30 espécies, 28 delas ocorrem na Floresta Atlântica, sendo 19 endêmicas (Sobral et al. 2009).

2. Campomanesia dichotoma (O. Berg) Mattos, Loefgrenia 26: 28. 1967.

Fig. 1d

Arvoretas ca. $4-7 \mathrm{~m}$ alt., ramos jovens pilosos. Folhas 7,5-11 × 4-6 cm, cartáceas, elípticas, acuminadas, atenuadas a levemente oblíqua; venação primária sulcada adaxialmente, secundária 6-8 pares, marginal a $1 \mathrm{~mm}$ da borda foliar; pecíolo 5-10 mm compr., piloso. Inflorescência dicásio, eixo primário $3 \mathrm{~cm}$ compr., eixo secundário $0,8 \mathrm{~cm}$ compr.; bractéolas $2 \mathrm{~mm}$ compr., lineares, pilosas; cálice piloso, lobos de comprimento igual, 3-4 mm compr., pilosos; hipanto $1 \mathrm{~mm}$ compr.; estames $8 \mathrm{~mm}$ compr., disco estaminal piloso; estilete $10 \mathrm{~mm}$ compr., glabro; ovário 8-10 locular. Frutos $0,8 \times 1,1 \mathrm{~cm}$, globoides, ápice constricto. Sementes $8-10,0,5-0,6 \times 0,4-0,5 \mathrm{~cm}$, reniformes, coloração uniforme, muricadas.

Material examinado: Mata de Piedade, 20.II.2009, fl., B.S. Amorim 387 et al. (UFP); Mata de Pezinho, 8.III.2009, fr., B.S. Amorim 406 et al. (UFP); 28.IV.2009, fr., B.S. Amorim $449 b$ et al. (UFP). 


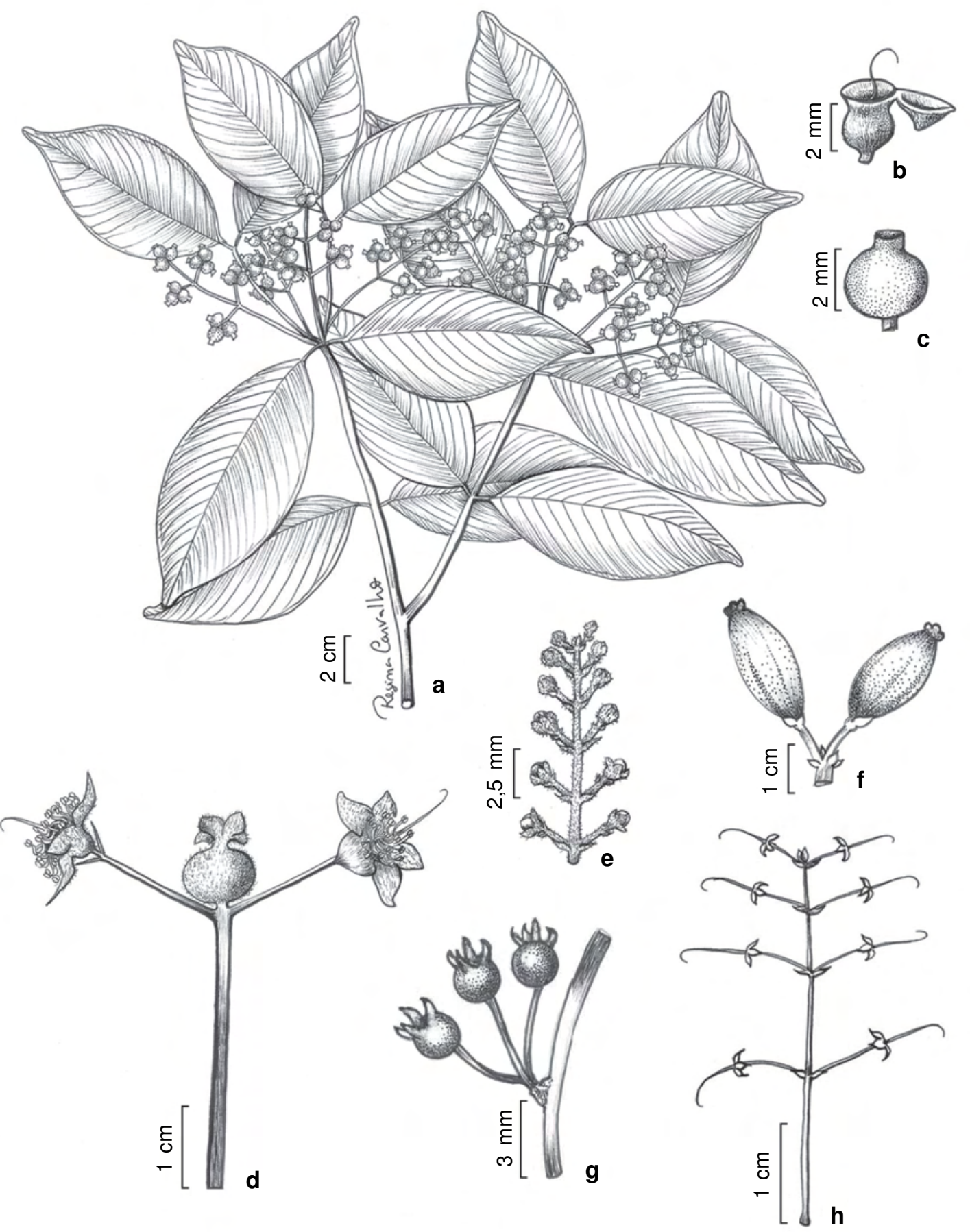

Figura 1 -a-c. Calyptranthes dardanoi-a. hábito; b. flor; c. fruto. d. Campomanesia dichotoma-inflorescência com flores e fruto. e. Eugenia candolleana - inflorescência com botões florais. f. Eugenia dichroma - infrutescência. g. Eugenia excelsa-infrutescência. h. Eugenia florida -inflorescência. (a B.S. Amorim 430; b B.S. Amorim 389a; c J.D. Garcia 1173; d B.S. Amorim 449b; e B.S. Amorim 444; f J.A.N. Souza 591; g B.S. Amorim 764 h E. Pessoa 108).

Figure 1 - a-c. Calyptranthes dardanoi - a. habit; b. flower; c. fruit. d. Campomanesia dichotoma - inflorescence with flower and fruit. e. Eugenia candolleana - inflorescence with flower bud. f. Eugenia dichroma - infructescence. g. Eugenia excelsa - infructescence. h. Eugenia florida - inflorescence. (a B.S. Amorim 430; b B.S. Amorim 389a; c J.D. Garcia 1173; d B.S. Amorim 449b; e B.S. Amorim 444; f J.A.N. Souza 591; g B.S. Amorim 764 h E. Pessoa 108). 
Endêmica da Floresta Atlântica (Sobral et al. 2009), conhecida para as Regiões NE e SE do Brasil (Landrum 1986). Na USJ, é uma espécie frequente sendo encontrada na borda dos fragmentos. Diferencia-se pela venação secundária com 6-8 pares, inflorescência em dicásio, ovário 8-10 locular e fruto com ápice constricto com sementes muricadas.

\section{Eugenia L., Sp. pl. 1: 470-471. 1753}

Arvoretas a arbustos. Inflorescência tipo racemo, eixo primário desenvolvido ou reduzido; cálice 4-mero, corola 4-mera; hipanto não prolongado acima do ovário; ovário 2-locular. Frutos globoides, subgloboides ou elipsoides, lisos ou verrucosos, lobos do cálice persistentes. Semente globoide ou elipsoide, lisa, coloração uniforme ou maculada.

Gênero com 600 espécies, 241 delas ocorrem na Floresta Atlântica, sendo 202 endêmicas (Sobral et al. 2009).

3. Eugenia candolleana DC., Prodr. 3: 281. 1828.

Fig 1e

Arvoretas a arbustos ca. 2-4 m alt., ramos jovens pilosos. Fohas 4-8 $82-3,5 \mathrm{~cm}$, membranáceas, elípticas, acuminadas, atenuadas; venação primária sulcada adaxialmente, secundária 8-10 pares, marginal a $1 \mathrm{~mm}$ da borda; pecíolos 3-5 mm compr., glabros. Inflorescência tipo racemo, eixo primário 1,5-2,5 cm compr., piloso, eixo secundário $0,5 \mathrm{~cm}$ compr.; brácteas ca. $1 \mathrm{~mm}$ compr., lanceoladas, margem e feixe central pilosos; bractéolas $1 \mathrm{~mm}$ compr. lanceoladas, margem e feixe central pilosos; cálice não segmentado, base pilosa, lobos de comprimento desigual, $1 \mathrm{~mm}$ e $2 \mathrm{~mm}$ compr., pilosos distalmente; estames 3-5 mm compr., disco estaminal piloso; estilete $6 \mathrm{~mm}$ compr., base pilosa. Frutos 1,4× $0,8 \mathrm{~cm}$, subgloboides, lisos, pilosos. Semente 1 , $1 \times 0,6 \mathrm{~cm}$, subgloboide, coloração uniforme.

Material examinado: Mata de Macacos, 14.III.2009, fl. e fr., B.S. Amorim 444 et al. (UFP).

Apesar de tratada por Sobral et al. (2009) como endêmica da Floresta Atlântica, Govaerts et al. (2010) cita a espécie para as Regiões CentroOeste e Norte do Brasil. Na USJ é uma espécie rara, encontrada no interior dos fragmentos, em habitats de tabuleiro e terraço. Diferencia-se pela inflorescência com eixo primário desenvolvido, disco estaminal piloso, estilete com base pilosa e fruto subgloboide.
4. Eugenia dichroma O. Berg in Mart., Fl. bras. 14(1): 290. 1859.

Fig. 1f

Arvoretas a arbustos $2-5 \mathrm{~m}$ alt., ramos jovens pilosos. Folhas 10-12×3-5 cm., cartáceas, elípticas, acuminadas, cuneadas; venação primária sulcada adaxialmente, venação secundária 14-16 pares, venação marginal a $2 \mathrm{~mm}$ da borda; pecíolo $5 \mathrm{~mm}$ compr., glabros. Inflorescência tipo racemo, eixo primário reduzido, eixo secundário 5-8 $\mathrm{mm}$ compr.; bráctea $1 \mathrm{~mm}$ compr., lanceolada, glabra; bractéola $2 \mathrm{~mm}$ compr., elíptica, margem hialina, glabra; cálice não segmentado, glabro, lobos de comprimento igual, 3-4 mm compr., glabros; estames $5 \mathrm{~mm}$ compr., disco estaminal piloso; estilete $4 \mathrm{~mm}$ compr., glabro. Frutos 1,5-2,5 ×1-1,5 cm, elipsoides, lisos, glabros. Semente 1, 2-2,5×1,5 cm, elipsoide, maculada.

Material examinado: Mata de Macacos, 3.V.2003, fl., A.Oliveira 7 et al. (PEUFR); Mata de Macacos, 24.III.2011, fl., B.S. Amorim 831 et al. (UFP); Mata de Piedade, 17.XII.2009, fr., J.A.N. Souza 591 et al. (UFP).

Endêmica da Floresta Atlântica (Sobral et al. 2009) e conhecida para as regiões NE e SE do Brasil (Govaerts et al. 2010; Proença \& Sobral 2006). Na USJ é uma espécie rara e coletada no interior de fragmentos, em habitats de tabuleiro e terraço. Diferencia-se pela inflorescência com eixo primário reduzido, disco estaminal piloso e fruto elipsoide com semente maculada.

5. Eugenia excelsa O. Berg in Mart., Fl. bras. 14(1): 227. 1857.

Fig. $1 \mathrm{~g}$

Arbustos a árvores 3-8 $\mathrm{m}$ alt. Folhas $8-13 \times$ 2,8-5 cm, cartáceas, elípticas, acuminadas, atenuadas, venação primária plana a saliente adaxialmente, secundária $8-10$ pares, marginal $1 \mathrm{~mm}$ da borda; pecíolo 3-4 mm compr., glabro. Inflorescência tipo racemo, eixo primário reduzido, secundário 4-10 mm compr., glabro; brácteas 2$3 \mathrm{~mm}$ compr., elípticas, glabras, bractéola $1 \mathrm{~mm}$ compr., linear, glabra; cálice não segmentado, glabro, lobos de mesmo comprimento $2 \mathrm{~mm}$ compr., agudos, glabros; estames $3 \mathrm{~mm}$ compr., disco estaminal glabro; estilete $4 \mathrm{~mm}$ compr., glabro. Frutos $0,6 \times$ $0,6 \mathrm{~cm}$, globoides, lisos, glabros. Semente $0,6 \times$ $0,6 \mathrm{~cm}$, globoide, coloração uniforme.

Material examinado: Mata de Piedade, 16.II.2011, fr., B.S. Amorim 764 et al. (UFP).

Material adicional: PERNAMBUCO: Goiana, Ponta de Pedra, 9.II.1968, fl., A. Lima 60-68 (IPA).

Distribui-se das Guianas até o Brasil (Govaerts et al. 2010), onde ocorre nas Regiões Norte, Nordeste, Sudeste e Sul (Sobral et al. 2010). $\mathrm{Na}$ USJ é uma espécie rara e encontrada no interior 
de fragmentos, em habitats de tabuleiro. Diferencia-se pelas folhas $8-13 \times 2,8-5 \mathrm{~cm}$, venação primária plano-convexa adaxialmente, racemo com eixo primário reduzido, brácteas elípticas, bractéolas lineares, disco estaminal e estilete glabros e frutos globoides. Exemplares observados em ambiente de restinga em Pernambuco apresentam hábito arbustivo e folhas menores com 4-7,5 × 1,3-3,5 cm.

\section{Eugenia florida DC., Prodr. 3: 283. 1828.}

Fig. $1 \mathrm{~h}$

Arvoretas $6 \mathrm{~m}$ alt., ramos jovens pilosos. Folhas 7,5-12 × 2,5-4,5 cm, cartáceas, elípticas, acuminadas, atenuadas; venação primária sulcada adaxialmente, secundária 6-8 pares, marginal a $1 \mathrm{~mm}$ da borda; pecíolo 4-6 mm compr., glabros. Inflorescência tipo racemo, eixo primário desenvolvido, 2,6-4,5 cm compr., piloso, eixo secundário 0,5-1 cm compr.; brácteas 1-2 mm compr., lanceoladas, margem hialina, pilosa, bractéolas 0,5-1 mm compr., discoides, margem hialina, pilosa; cálice não segmentado, piloso, lobos de comprimento desigual, $1 \mathrm{~mm}$ e $2 \mathrm{~mm}$ compr., glabros, margem hialina, pilosa; estames 4-5 mm compr, disco estaminal glabro; estilete 5-6 mm compr., glabro. Frutos $0,8-1 \times 0,8-1 \mathrm{~cm}$, globoides, lisos, glabros. Semente $1,1 \times 0,8 \mathrm{~cm}$, subgloboide, coloração uniforme.

Material examinado: Mata de Piedade, 20.II.2009, fr., B.S. Amorim 389b et al. (UFP); 21.XI.2009, fl. E. Pessoa 108 et al. (UFP); 29.01.2010, B.S. Amorim 559 et al. (UFP).

Amplamente distribuída na América tropical (Govaerts et al. 2010) com ocorrência em todas as regiões do Brasil (Sobral et al., 2010). Na USJ é uma espécie ocasional e encontrada na borda e interior de fragmentos, em habitats de tabuleiro. Diferencia-se por apresentar inflorescência com eixo primário desenvolvido, disco estaminal glabro, estilete glabro e frutos subgloboides.

7. Eugenia hirta O. Berg. in Mart., Fl. bras. 14(1): 574. 1859.

Fig. 2a-b

Arbustos ca. 2-4 m alt., ramos jovens pilosos. Folhas 3-7,7 × 1,5-3,5 cm, membranáceas, ovadas, agudas, obtusas a truncadas; venação primária plana a saliente adaxialmente, pilosa, secundária 4-6 pares, marginal a $2 \mathrm{~mm}$ da borda; pecíolo 1-3 mm compr., piloso. Inflorescência tipo racemo, eixo primário reduzido, eixo secundário $7 \mathrm{~mm}$ compr., piloso; brácteas $1 \mathrm{~mm}$ compr., lanceoladas, pilosa; bractéolas $1 \mathrm{~mm}$ compr., lanceoladas, margem pilosa; cálice não segmentado, piloso, lobos de comprimento desigual, $3 \mathrm{~mm}$ e $2 \mathrm{~mm}$ compr., pilosos, extremidade hialina; estames $2-3 \mathrm{~mm}$, disco estaminal glabro; estilete $5 \mathrm{~mm}$, glabro. Frutos $0,8 \times$ $0,8 \mathrm{~mm}$, globoides, lisos, glabros. Semente 1, 0,60,7 ×0,6-0,7 mm, globoide, maculada.

Material examinado: Mata de Piedade, 26.I.2010, fl. e fr., B.S. Amorim 525 et al. (UFP).

Endêmica da Floresta Atlântica (Sobral et al. 2009), com distribuição conhecida para o NE e SE do Brasil (Sobral et al. 2010). Na USJ é uma espécie frequente e coletada no interior de fragmentos, ocupando o subdossel, em habitats de tabuleiro. Diferencia-se por apresentar inflorescência com eixo primário reduzido, disco estaminal glabro, estilete glabro e fruto globoso com semente maculada.

8. Eugenia aff. prasina O. Berg in Mart., Fl. bras. 14(1): 255.1857.

Fig 2c

Árvore $8 \mathrm{~m}$ alt., ramos jovens pilosos. Folhas 10-14,5 × 5,5-6,5 cm, cartáceas, elípticas a obovadas, acuminadas, atenuadas, venação primária sulcada adaxialmente, secundárias 10 pares, marginal $2 \mathrm{~mm}$ da borda; pecíolo 1,3-1,5 cm compr., glabro. Inflorescência tipo racemo, eixo primário reduzido, secundários $1 \mathrm{~cm}$ compr.; brácteas $2 \mathrm{~mm}$ compr., lanceoladas, glabras; bractéolas $5 \mathrm{~mm}$ compr., lineares, glabras; cálice glabro, lobos 4-5 mm compr., elípticos, ápice agudo, glabros; estames não observados, disco estaminal glabro; estilete não observado. Fruto 2,5-3,5 × 1,7-2,4 cm, elipsoide, rugoso, glabro. Semente 2,4-3,3 × 1,6-2,3, elipsoide, maculada.

Material examinado: Mata de Cruzinha, 2.XII.2010, fr., B.S. Amorim 691 et al. (UFP).

Na USJ, é uma espécie muito rara e encontrada no interior dos fragmentos, em habitats de terraço. Diferencia-se das demais Eugenia pelas folhas 1014,5 × 5,5-6,5, venação primária côncava adaxialmente, racemo com eixo primário reduzido, disco estaminal glabro, estilete glabro e fruto elipsoides, rugosos.

9. Eugenia punicifolia (Kunth) DC., Prodr. 3: 267. 1828.

Fig. 2d

Arbustos 1 a $3 \mathrm{~m}$ alt., ramos jovens pilosos. Folhas 3-5,5 × 1-2,5 cm, cartáceas, elípticoobovadas, acuminadas, atenuadas; venação primária sulcada adaxialmente, secundária 8-10 pares, marginal a $3 \mathrm{~mm}$ da borda; pecíolo $3-4 \mathrm{~mm}$, glabros. Inflorescência em racemo, eixo primário não desenvolvido, eixos secundários 2, $10 \mathrm{~mm}$ 


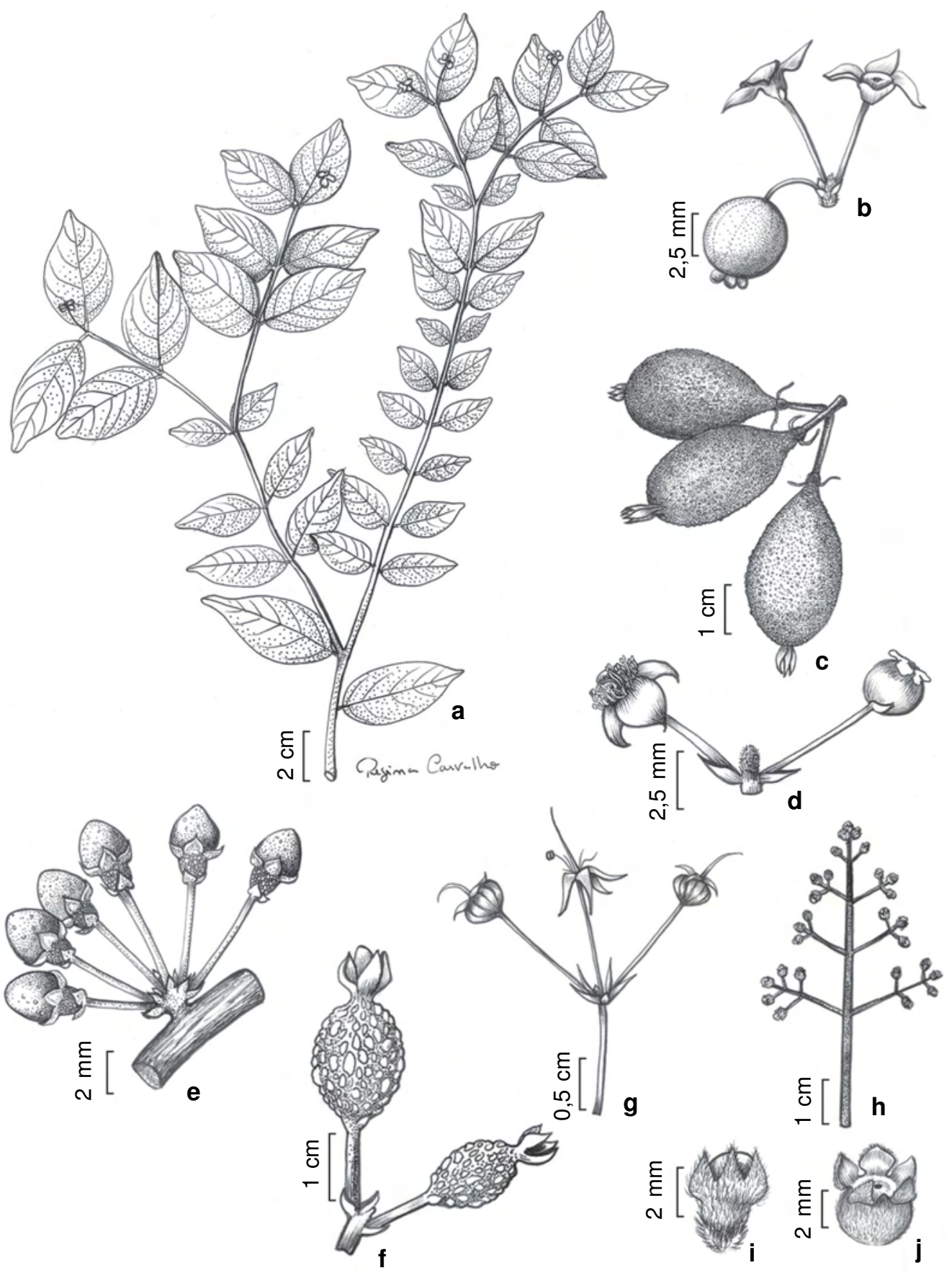

Figura 2 - a-b. Eugenia hirta - a. hábito; b. infrutescência. c. Eugenia aff. prasina - infrutescência. d. Eugenia punicifolia infrutescência. e. Eugenia umbelliflora - inflorescência com botões florais. f. Eugenia umbrosa-inflorescência com frutos. g. Eugenia uniflora - inflorescência com flor e frutos. h-j. Myrcia bergiana - h. inflorescência; i. botão floral; j. fruto. (a B.S. Amorim 645; b - B.S. Amorim 529; c B.S. Amorim 691 d B.S. Amorim 524; e T.N.F. Guerra 120; f B.S. Amorim 424; g B.S. Amorim 320; h B.S. Amorim 433; i B.S. Amorim 479; j.M. Nascimento 681).

Figure 2 - a-b. Eugenia hirta - a. habit.; b. infructescence. c. Eugenia aff. prasina d. Eugenia punicifolia - inflorescence with flower and fruit. e. Eugenia umbelliflora - inflorescence with flower bud. f. Eugenia umbrosa - infructescence. g. Eugenia uniflora - inflorescence with flower and fruit. h-j. Myrcia bergiana - h. inflorescence; i. flower bud; j. fruit. (a B.S. Amorim 645; b B.S. Amorim 529; c B.S. Amorim 691 d B.S. Amorim 524; e T.N.F. Guerra 120; f B.S. Amorim 424; g B.S. Amorim 320; h B.S. Amorim 433; i B.S. Amorim 479; j L.M. Nascimento 681). 
compr.; brácteas 2, $1 \mathrm{~mm}$ compr., lanceoladas, pilosas; bractéolas $1 \mathrm{~mm}$ compr., rotundas, margem pilosa; cálice não segmentado, glabro, lobos de comprimento desigual, 2, $2 \mathrm{~mm}$ e 2,1 $\mathrm{mm}$ compr., glabros, extremidade hialina; estames 4 $5 \mathrm{~mm}$ compr., disco estaminal com margem pilosa; estilete 5-6 mm compr., glabro. Frutos 0,9-1,2 $\times$ 0,7-0,9 cm, subgloboides, lisos, glabros. Semente $1,0,8-1,1 \times 0,6-0,8 \mathrm{~cm}$, globoide a elipsoide, coloração uniforme.

Material examinado: Mata de Vespas, 12.III.2009, fr., B.S. Amorim 423 et al. (UFP); 12.I.2010, fl., B.S. Amorim 524 et al. (UFP).

Amplamente distribuída, desde Cuba até a América tropical (Govaerts et al. 2010), ocorrendo em todas as regiões do Brasil (Sobral et al. 2010). Na USJ é uma espécie ocasional e encontrada na borda de fragmentos. Diferencia-se por apresentar inflorescência com eixo primário não desenvolvido e apenas dois eixos secundários, bractéolas rotundas, disco estaminal com margem pilosa, estilete glabro e fruto globoide a elipsoide.

10. Eugenia umbelliflora O. Berg in Mart., Fl. bras. 14(1):290. 1859.

Fig. 2e

Arvoretas $6 \mathrm{~m}$ alt., ramos jovens pilosos. Folhas 5-9,5 × 3-4,5 cm, cartáceas, elípticas, arredondadas, atenuadas, venação primária plana a saliente adaxialmente, glabra, secundária 8 pares, marginal a $3 \mathrm{~mm}$ compr. da borda; pecíolo $4 \mathrm{~mm}$ compr., glabro. Inflorescência tipo racemo, eixo primário reduzido, eixo secundário $2-5 \mathrm{~mm}$ compr.; brácteas $1 \mathrm{~mm}$ compr., lanceoladas, glabras, bractéolas $1 \mathrm{~mm}$ compr., lanceoladas, glabras; cálice não segmentado, glabro, lobos de comprimento igual, $1 \mathrm{~mm}$ compr., margem pilosa; estame $3 \mathrm{~mm}$ compr., disco estaminal glabro; estilete $4-5 \mathrm{~mm}$ compr., glabro. Frutos $0,8 \times 1 \mathrm{~cm}$ compr., subgloboides, lisos, glabros. Semente 1, 0,8 $\times 0,7$ $\mathrm{cm}$, subgloboide, coloração uniforme.

Material examinado: Mata de Piedade, 20.XII.2007, fr., D. Araújo 539 et al. (UFP); Mata de Chave, 8.IV.2008, fl., T.N.F. Guerra 120 et al. (UFP); Mata de Vespas, 12.III.2009, B.S. Amorim 426 et al. (UFP).

Endêmica da Floresta Atlântica (Sobral et al. 2009) e com ocorrência do Nordeste a Santa Catarina (Govaerts et al. 2010; Proença \& Sobral 2006). Na USJ é uma espécie rara e encontrada no interior de fragmentos, em habitats de tabuleiro. Diferencia-se por apresentar inflorescência com eixo primário reduzido, disco estaminal glabro e frutos subgloboides.
11. Eugenia umbrosa O. Berg in Mart., Fl. bras. 14(1):582. 1859 .

Fig. $2 \mathrm{f}$

Arvoretas 3-7 m alt., ramos jovens pilosos. Folhas 10,5-27 ×5,5-7,5 cm, cartáceas, obovadas, acuminadas, atenuadas; venação primária plana a saliente adaxialmente, secundária 10-12 pares, marginal 3-4 mm da borda foliar; pecíolo 8-11 mm compr., glabro. Inflorescência tipo racemo, eixo primário reduzido, eixo secundário $10-13 \mathrm{~mm}$ compr., glabro; brácteas 3-5 mm compr., linearlanceoladas, glabras; bractéolas $2 \mathrm{~mm}$ compr., discoide-lanceoladas; cálice não segmentado, lobos de comprimento igual, 8-10 mm compr., glabros; estames $8 \mathrm{~mm}$ compr., disco estaminal glabro; estilete $12 \mathrm{~mm}$ compr., glabro. Frutos 3,3 $\times 2,2 \mathrm{~cm}$, elipsoides, verrucosos, glabros. Semente $1,3 \times 1,8 \mathrm{~cm}$, elipsoide, maculada.

Material examinado: Mata de Vespas, 12.III.2009, fl. e fr., B.S. Amorim 424 et al. (UFP); Mata de Zambana, 30.VIII.2008, fr., M.A.M. Silva 38 et al. (UFP).

Endêmica da Floresta Atlântica (Sobral et al. 2009) e conhecida para as regiões Nordeste e Sudeste do Brasil (Govaerts et al. 2010; Proença \& Sobral 2006). Na USJ é uma espécie rara, encontrada no interior dos fragmentos, em habitats de tabuleiro, terraço e sítio ripário. Diferencia-se por apresentar inflorescência com eixo primário reduzido e frutos elipsoides, verrucosos com semente elipsoide e maculada.

12. Eugenia uniflora L., Sp. pl. 1: 470-471. 1753.

Fig. $2 \mathrm{~g}$

Arbustos $2-4 \mathrm{~m}$ alt., ramos jovens pilosos. Folhas 3-5,5×1,2-3 cm, membranáceas, elípticas, acuminadas, atenuadas; venação primária plana a saliente adaxialmente, secundária 5-7 pares, marginal $2 \mathrm{~mm}$ da borda foliar; pecíolo $2 \mathrm{~mm}$ compr., glabro. Inflorescência tipo racemo, eixo primario reduzido, eixo secundário 15-20 mm compr, glabro; brácteas 2-3 mm compr, elípticas, ápice piloso; bractéolas 1-2 mm compr., lineares, glabras; cálice 8-segmentado, glabro; lobos de comprimento igual, 2-4 mm compr., glabros; estames 3-4 mm compr., disco estaminal piloso; estilete 3-4 $\mathrm{mm}$ compr., glabro. Frutos $1,8 \times 2 \mathrm{~cm}$, subgloboides, 8 -costados, lisos, glabros. Sementes $1-2,0,8 \times 1 \mathrm{~cm}$, subgloboides, coloração uniforme.

Material examinado: Mata de Piedade, 26.12.2008, fl. e fr., B.S. Amorim 320 et al. (UFP).

Material adicional: PERNAMBUCO: Recife, Dois Irmãos, 25.VIII.1988, fl. e fr., V. Ferreira 1 et al. (IPA); 12.IX.1991, fl. e fr., $R$. Salgado s/ $n$ et al. (IPA 55204). 
Conhecida desde o Nordeste do Brasil ao sul da América do sul, além de ser amplamente cultivada pelos frutos comestíveis (Govaerts et al. 2010, Proença \& Sobral 2006). Na USJ é uma espécie ocasional, encontrada na borda dos fragmentos e em ambientes com maior nível de antropização. Diferencia-se por apresentar inflorescência com eixo primário reduzido, cálice 8-costado, disco estaminal piloso e frutos subgloboides 8-costados com semente de coloração uniforme.

Myrcia DC. ex Guill., Dict. Class. Hist. Nat. 11: 378, 401, 406. 1827.

Árvores ou arvoretas. Inflorescência tipo panícula; cálice 5-mero, corola 5-mera; hipanto prolongado acima do ovário; ovário 2-3-locular. Frutos elipsoides, globoides ou subgloboides, lisos ou verrucosos, lobos do cálice persistentes. Sementes subgloboides a elipsóides, coloração uniforme ou maculadas.

Gênero com 350 espécies, 132 delas ocorrendo na Floresta Atlântica, sendo 101 endêmicas (Sobral et al. 2009).

13. Myrcia bergiana O. Berg in Mart., Fl. bras. 14(1): 194.1857.

Fig. $2 \mathrm{~h}-\mathrm{j}$

Arvoretas 3-7 m alt., ramos jovens pilosos, ferrugíneos. Folhas 5-10 × 2,8-4 cm, cartáceas, elípticas, acuminadas, obtusas; venação primária plana a saliente adaxialmente, pilosa (ferruginea), secundária 18 pares, marginal 1-2 mm da borda foliar; pecíolo $8 \mathrm{~mm}$ compr., piloso. Inflorescência tipo panícula, eixo primário $8 \mathrm{~cm}$ compr., ramificação até segunda ordem; brácteas $2 \mathrm{~mm}$ compr., lineares, pilosas; bractéolas $1 \mathrm{~mm}$ compr., lanceoladas, pilosas; cálice piloso, lobos de comprimento igual, $2 \mathrm{~mm}$ compr., não imbricados ápice agudo, pilosos; hipanto $1 \mathrm{~mm}$ compr.; estames $3 \mathrm{~mm}$ compr., disco estaminal piloso; estilete 4-5 mm compr., piloso; ovário 2-locular Frutos $0,7 \times 0,7 \mathrm{~cm}$, globoides, lisos, pilosos. Sementes $1-2,0,5 \times 0,5 \mathrm{~cm}$, subgloboides, coloração uniforme.

Material examinado: Mata de Macacos, 17.IV.2008, fr., L.M. Nascimento 681 et al. (UFP); Mata de Pezinho, 8.III.2009, fl., B.S. Amorim 407 et al. (UFP); Mata de Cruzinha, fl., B.S. Amorim 433 et al. (UFP).

Endêmica da Floresta Atlântica (Sobral et al. 2009) e conhecida para as Regiões Nordeste (Proença \& Sobral 2006) e sudeste do Brasil (Sobral et al. 2010). Na USJ é uma espécie rara tendo sido coletada na borda e interior dos fragmentos, em habitats de tabuleiro. Diferencia-se pela pilosidade ferrugínea, lobos do cálice de comprimento igual, apiculados e frutos globoides.

14. Myrcia guianensis (Aubl.) DC., Prodr. 3: 245. 1828.

Fig. 3a-b

Arvoretas a árvores 3-8 $\mathrm{m}$ alt., ramos jovens pilosos. Folhas 3-7,5 × 1,5-3,5 cm, membranáceas, elípticas, obtusas, agudas a cuneadas; venação primária plana a saliente adaxialmente, secundária 10-12 pares, marginal $1 \mathrm{~mm}$ da borda foliar; pecíolo 3-5 mm compr., piloso. Inflorescência tipo panícula, eixo primário $10 \mathrm{~cm}$ compr., ramificação até segunda ordem; brácteas $2 \mathrm{~mm}$ compr., lanceoladas, pilosas; bractéolas $1 \mathrm{~mm}$ compr., lineares, pilosas; cálice glabro; lobos de comprimento desigual, 3 maiores, 2 mm compr., 2 menores, $1 \mathrm{~mm}$ compr., não imbricados, ápice rotundo, piloso; hipanto $1 \mathrm{~mm}$ compr.; estames $4 \mathrm{~mm}$ compr., disco estaminal glabro; estilete 5-6 mm compr., glabro; ovário 3locular. Frutos 0,6-0,8 ×0,6-1 cm, subgloboides, lisos, glabros. Sementes 1-3, 0,6 × 0,5 cm, subgloboides, coloração uniforme.

Material examinado: Mata de Piedade, 20.II.2009, fl., B.S. Amorim 445 et al. (UFP); Mata de Pezinho, 8.III.2009, fr., B.S. Amorim 411 et al. (UFP); Mata de Macacos, 14.III.2009, fr., B.S. Amorim 443 et al. (UFP).

Amplamente distribuída na América do Sul, desde Trinidad e Tobago até o Paraguai (Govaerts et al. 2010) e ocorre em todas as Regiões do Brasil (Sobral et al. 2010). Na USJ é uma espécie comum e encontrada na borda e interior de fragmentos, em habitats de tabuleiro. Diferencia-se por apresentar cálice com lobos de comprimento desigual, sendo 3 maiores com $2 \mathrm{~mm}$ compr. e 2 menores com $1 \mathrm{~mm}$ compr., ápice rotundo; ovário 3-locular e frutos subgloboides.

15. Myrcia racemosa (O.Berg) Kiaersk., Enum. Myrt. bras.: 72.1893.

Fig. 3c-d

Arvoretas 3-7 $\mathrm{m}$ alt., ramos jovens pilosos. Folhas 6-9 × 3-3,5 cm, cartáceas, elípticas, acuminadas, atenuadas; venação primária plana a saliente adaxialmente, secundária 14-16 pares, marginal $1 \mathrm{~mm}$ da borda foliar; pecíolo $5 \mathrm{~mm}$ compr., glabros. Inflorescência tipo panícula, eixo primário $8 \mathrm{~cm}$ compr., ramificação até terceira ordem; brácteas $2 \mathrm{~mm}$ compr., lanceoladas, pilosas; bractéolas $1 \mathrm{~mm}$ compr., lanceoladas, pilosas; cálice glabro, lobos de comprimento igual $2 \mathrm{~mm}$ compr., não imbricados, ápice agudo, glabros; hipanto $1 \mathrm{~mm}$ compr.; estame $3 \mathrm{~mm}$ compr., disco estaminal glabro; estilete $4 \mathrm{~mm}$ compr., glabro; ovário 2-locular. Frutos 0,6 × 0,6- 

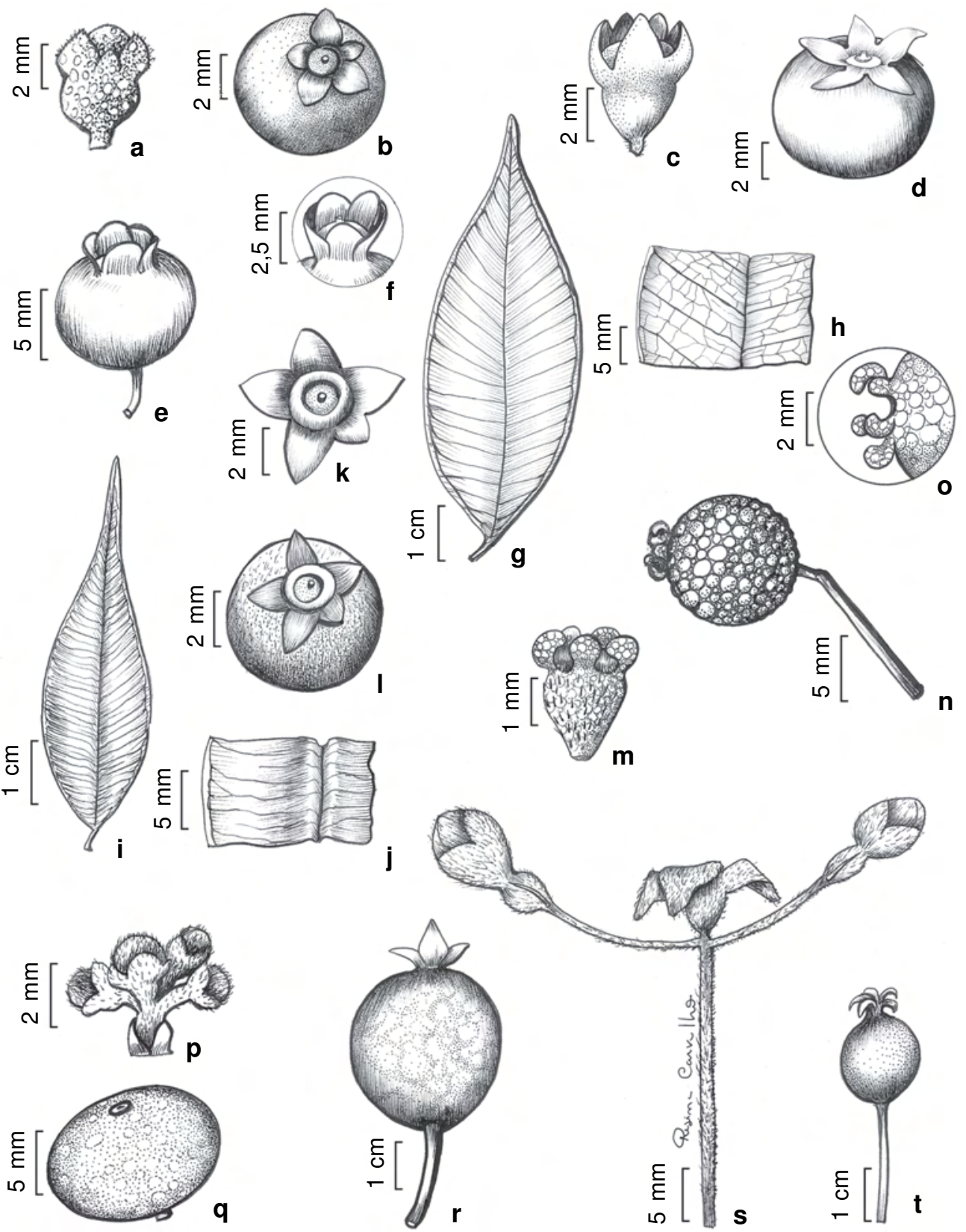

Figura 3 - a-b. Myrcia guianensis - a. botão floral; b. fruto. c-d. Myrcia racemosa - c. botão floral; d. fruto. e-f. Myrcia spectabilis e. fruto; f. detalhe dos lobos do cálice. g-h. Myrcia splendens - g. folha; h. detalhe da venação primária. i-j. Myrcia sylvatica-i. folha; j. detalhe da venação primária. k-1. Myrcia tomentosa-k. detalhe dos lobos do cálice; 1. fruto.m-o. Myrcia verrucosa-m. botão floral; n. fruto; o. detalhe dos lobos do cálice. p-q. Myrciaria ferruginea - p. inflorescência com botões florais; q. fruto. r. Psidium guajava fruto. s-t. Psidium guineense-s. inflorescência com botões florais e parte de uma flor; t. fruto. (a B.S. Amorim 445; b B.S. Amorim 411; c D. Cavalcanti 32; d B.S. Amorim 454; e-fJ.A.N. Souza 630; g-h B.S. Amorim 388; i-j B.S. Amorim 318; k-1 B.S. Amorim 422; $\mathrm{m}$ D.R. Siqueira 120; n-o A.C.B. Lins e Silva 355; p-q B.S. Amorim 438; r B.S. Amorim 499; s B.S. Amorim 421; t B.S. Amorim 494).

Figure 3 - a-b. Myrcia guianensis - a. flower bud; b. fruit. c-d. Myrcia racemosa - c. flower bud; d. fruit. e-f. Myrcia spectabilis - e. fruit; f. calyx lobe detail. g-h. Myrcia splendens - g. leaf; h. main leaf vein detail. i-j. Myrcia sylvatica - i. leaf; j. main leaf vein detail. k-1. Myrcia tomentosa -k. calyx lobe detail; 1. fruit. m-o. Myrcia verrucosa - m. flower bud; $n$. fruit; o. calyx lobe detail. p-q. Myrciaria ferruginea - p. inflorescence with flower bud; q. fruit. r. Psidium guajava - fruit. s-t. Psidium guineense - s. inflorescence with flower bud; t. fruit. (a B.S. Amorim 445; b B.S. Amorim 411; c D. Cavalcanti 32; d B.S. Amorim 454; e-f J.A.N. Souza 630; g-h B.S. Amorim 388; i-j B.S. Amorim 318; k-1 B.S. Amorim 422; $\mathrm{m}$ D.R. Siqueira 120; n-o A.C.B. Lins e Silva 355; p-q B.S. Amorim 438; r B.S. Amorim 499; s B.S. Amorim 421; t B.S. Amorim 494). 
$0,8 \mathrm{~cm}$, globoides a subgloboides, lisos, glabros. Semente $1-2,0,5 \times 0,6 \mathrm{~cm}$, subgloboides, coloração uniforme.

Material examinado: Mata de Pezinho, 28.IV.2009, fr., B.S. Amorim 454 et al. (UFP); Mata de Piedade, 17.XII.2009, fl., D. Cavalcanti 32 et al. (UFP); 02.III.2010, fr., B.S. Amorim 562 et al. (UFP).

Endêmica da Floresta Atlântica (Sobral et al. 2009), com ocorrência de Pernambuco a Santa Catarina (Govaerts et al. 2010; Proença \& Sobral 2006). Na USJ é uma espécie rara encontrada no interior de fragmentos, em habitats de tabuleiro e terraço. Espécie morfologicamente próxima de Myrcia splendens, porém diferencia-se por apresentar cálice com lobos acuminados, disco estaminal glabro e fruto globoide a sub-globoide.

\section{Myrcia spectabilis DC., Prodr. 3: 248. 1828.}

Fig. 3e-f

Arvoretas $6 \mathrm{~m}$ alt, ramos jovens pilosos. Folhas 12-15 × 3,5-5,5 cm, coriáceas, elípticas, acuminadas, atenuadas; venação primária sulcada adaxialmente, secundária 12-16 pares, marginal 3 $\mathrm{mm}$ da borda foliar; pecíolo $5 \mathrm{~mm}$ compr. Inflorescência tipo panícula, eixo primário $7 \mathrm{~cm}$ compr., ramificação até terceira ordem; brácteas decíduas, bractéolas $2 \mathrm{~mm}$ compr., lanceoladas, pilosas; cálice piloso, lobos iguais entre si, $4 \mathrm{~mm}$ compr., imbricados, ápice apiculado, pilosos; hipanto $2 \mathrm{~mm}$ compr.; estames $3 \mathrm{~mm}$ compr., disco estaminal piloso; estilete 4-5 mm compr., base pilosa. Frutos globoides $1 \times 1 \mathrm{~cm}$, pilosos, lisos. Semente 1(2), $1 \times$ $0,8 \mathrm{~cm}$, subgloboides, coloração uniforme.

Material examinado: Mata de Piedade, 27.I.2010, fr., B.S. Amorim 553 et al. (UFP); 2.III.2010, fr., J.A.N. Souza 630 et al. (UFP); 9.III.2010, fr., B.S. Amorim 592 et al. (UFP).

Endêmica da Floresta Atlântica (Sobral et al. 2009), distribuição do Nordeste ao Sul do Brasil (Govaerts et al. 2010; Proença \& Sobral 2006). Na USJ é uma espécie rara encontrada no interior dos fragmentos, em habitats de tabuleiro, terraços e sítio ripário. Diferencia-se pelo cálice com lobos de igual tamanho, imbricados e com ápice apiculado, disco estaminal piloso, estilete com base pilosa e frutos globoides.

17. Myrcia splendens (Sw.) DC., Prodr. 3: 244. 1828.

Fig. 3g-h

Arvoretas 3-7 m alt., ramos jovens pilosos. Folhas 5-12×2-5 cm, cartáceas, elípticas, acuminadas, atenuadas; venação primária plana a saliente adaxialmente, pilosa, secundária 12-14 pares, marginal
$1 \mathrm{~mm}$ da borda foliar; pecíolo 3-5 mm compr., piloso. Inflorescência em panícula, eixo primário $9 \mathrm{~cm}$ compr., ramificada até a quarta ordem; brácteas 2$4 \mathrm{~mm}$ compr., lanceoladas a romboideas; bractéolas 1-2 mm compr., lineares, pilosa; cálice piloso; lobos de comprimento igual, $1 \mathrm{~mm}$ compr., não imbricados, ápice rotundo, margem pilosa; hipanto $1 \mathrm{~mm}$ compr.; estames 3-4 mm compr., disco estaminal piloso; estiletes 5-6 mm, base pilosa; ovário 2-locular. Frutos $1 \times 0,6 \mathrm{~cm}$, elípsoides, pilosos, lisos. Semente $1,0,7 \times 0,5 \mathrm{~cm}$, elipsoide, coloração uniforme.

Material examinado: Mata de Piedade, 20.II.2009, fl., B.S. Amorim 388 et al. (UFP); Mata de Zambana, 13.III. 2009, fr., B.S. Amorim 435 et al. (UFP).

Amplamente distribuída na América do Sul, desde o México a Argentina, ocorre em todas as regiões do Brasil (Govaerts et al. 2010; Sobral et al. 2010). Na USJ é uma espécie comum e encontrada na borda e interior de fragmentos, em habitats de tabuleiro e sítio ripário. Morfologicamente similar a Myrcia sylvatica da qual diferencia-se pela venação primária plano-convexa adaxialmente.

18. Myrcia sylvatica (G. Mey.) DC., Prodr. 3: 244. 1828.

Fig. $3 i-j$

Arvoretas 3-7 $\mathrm{m}$ alt., ramos jovens pilosos. Folhas 4-6 × 1,5-2 cm, cartáceas, ovadas, acuminadas, cuneadas; venação primária sulcada adaxialmente, secundária 18 pares, marginal $0,5 \mathrm{~mm}$ da borda foliar; pecíolo $1 \mathrm{~mm}$ compr., glabro. Inflorescência tipo panícula, eixo primário $3 \mathrm{~cm}$ compr., ramificação até terceira ordem; brácteas $2 \mathrm{~mm}$ compr., elípticas, pilosas; bractéolas $2 \mathrm{~mm}$ compr., lineares, pilosas; cálice piloso, lobos de comprimento igual, não imbricados, ápice rotundo, pilosos; hipanto $1 \mathrm{~mm}$ compr., piloso; estames 2-3 mm, disco estaminal piloso; estiletes 3-4 mm, base pilosa; ovário 2locular. Frutos $1,1 \times 0,5 \mathrm{~cm}$, elipsoides, lisos, glabros; Semente 1, 0,9 ×0,4 cm, elipsoide, coloração uniforme.

Material examinado: Mata de Pezinho, 28.IV.2009, fr., B.S. Amorim 453 et al. (UFP); 10.VII.2009, fl., B.S. Amorim 408 et al. (UFP); Mata de Zambana, 28.I.2010, fl., B.S. Amorim 555 et al. (UFP).

Amplamente distribuída na América do Sul, desde a Costa Rica até o Brasil onde ocorre em todas as Regiões (Govaerts et al. 2010; Sobral et al. 2010). Na USJ é uma espécie comum e encontrada na borda e interior dos fragmentos, em habitat de tabuleiro. Espécie morfologicamente semelhante a Myrcia splendens da qual diferencia-se pela venação primária côncava adaxialmente. 
19. Myrcia tomentosa (Aubl.) DC., Prodr. 3: 245. 1828.

Fig. 3k-1

Arvoretas 5-7 m alt., ramos jovens pilosos. Folhas 4-8 × 2,5-4,5 cm, cartáceas, elípticas ou obovadas, apiculadas ou acuminadas, atenuadas, venação primária sulcada adaxialmente, pilosa, secundária 6-8 pares, marginal $1-3 \mathrm{~mm}$ da borda foliar; pecíolo $5 \mathrm{~mm}$ compr., piloso. Inflorescência tipo panícula, eixo primário $13 \mathrm{~cm}$ compr., ramificação até terceira ordem; brácteas 3-4 mm compr., elípticolanceolada, pilosa; bractéolas $1 \mathrm{~mm}$ compr., elípticas, glabras; cálice piloso, lobos de comprimento desigual, 4 maiores, $2 \mathrm{~mm}$ compr., 1 menor, $1 \mathrm{~mm}$ compr., não imbricados, ápice agudo, pilosos; hipanto $1 \mathrm{~mm}$ compr.; estames $4 \mathrm{~mm}$ compr., disco estaminal glabro a piloso; estilete $6 \mathrm{~mm}$ compr., glabro a piloso; ovário 2-locular. Frutos 0,5-0,6 cm, subgloboides, lisos, pilosos. Semente $1-2,0,4 \times 0,3 \mathrm{~cm}$, subgloboides, coloração uniforme. Material examinado: Mata de Zambana, 22.XII. 2007, fl., A. Alves-Araújo 764 etal. (UFP); Mata de Piedade, 11.III.2009, fr., B.S. Amorim 419 et al. (UFP); Mata de Macacos, 14.III.2009, fr., B.S. Amorim 442 et al. (UFP); Mata de Zambana, 28.I.2010, fr., B.S. Amorim 556 et al. (UFP).

Amplamente distribuída na América do Sul, desde Trinidad e Tobago e Panamá até o Brasil (Govaerts et al. 2010), ocorre em todas as regiões do Brasil (Sobral et al. 2010). Na USJ é uma espécie comum e encontrada na borda dos fragmentos. Diferencia-se por apresentar venação secundária com 6-8 pares; cálice com lobos desiguais, sendo, 4 maiores com $2 \mathrm{~mm}$ compr. e 1 menor com $1 \mathrm{~mm}$ compr., acuminados e frutos subgloboides.

\section{Myrcia verrucosa Sobral, Bol. Mus. Biol. Mello} Leitão. 20: 77. 2006.

Fig. 3m-o

Arvoretas 5-7 m alt, ramos jovens pilosos. Folhas 4,5-8 × 2,5-4 cm, cartáceas, elípticas, apiculadas, atenuada; venação primaria sulcada adaxialmente, secundária 10-12 pares, marginal a $2 \mathrm{~mm}$ da borda foliar; pecíolo 5-8 $\mathrm{mm}$ compr., glabros. Inflorescência tipo panícula, raque glabra, eixo primário $8 \mathrm{~cm}$ compr., secundário (2-3) 2,5-1,5 cm compr.; brácteas decíduas; bractéolas 0,8-2 mm compr., lineares, pilosas; cálice piloso, lobos não diferenciados, não imbricados, ápice falciforme; hipanto $1 \mathrm{~mm}$ compr.; estames $3-4 \mathrm{~mm}$ compr., disco estaminal glabro ; estilete $5 \mathrm{~mm}$ compr., glabro; ovário 2-locular. Frutos $0,8-1 \times 0,8-1 \mathrm{~cm}$, globoides, verrucosos, glabros. Sementes $1-2,0,8 \times 0,7 \mathrm{~cm}$, subgloboide, maculada.

Material examinado: Mata de Zambana, 19.VII.2008, fr., A.C.B. Lins e Silva 355 et al. (UFP).
Material adicional: PERNAMBUCO: Cabo de Santo Agostinho, Mata do Zumbí, 1.XI.1995, fl., D.R. Siqueira 120 et al. (PEUFR).

Endêmica da Floresta Atlântica e conhecida até então apenas para o estado do Espírito Santo (Sobral 2006; Sobral et al. 2010). Na USJ, é uma espécie muito rara e encontrada no interior dos fragmentos, em habitats de terraço. Diferencia-se por apresentar venação primária côncava adaxialmente; cálice com lobos com ápice falciforme e frutos subgloboides e verrucosos.

Myrciaria O. Berg, Linnaea 27(2-3): 136, 320. 1854. Arbustos. Inflorescência tipo racemo; cálice 4-mero; corola 4-mera, cálice com lobos de comprimento igual; hipanto prolongado acima do ovário; ovário 2-locular. Frutos subgloboides, cálice decíduo. Semente globoide, maculada.

Gênero com distribuição na América Tropical (Govaerts et al. 2010), representado por 30 espécies, 15 delas ocorrem na Floresta Atlântica, sendo 10 endêmicas (Sobral et al. 2009).

21. Myrciaria ferruginea $\mathrm{O}$. Berg, in Martius, Fl. bras. 14(1): 597. 1859.

Fig. 3p-q

Arbustos a subarbustos $0,5-2 \mathrm{~m}$ alt., ramos pilosos. Folhas 1,5-3 × 1-1,2 cm, membranáceas, ovadas, atenuadas, obtusas; venação primária sulcada adaxialmente, secundária 10-12 pares, 1 mm da margem; pecíolo $1 \mathrm{~mm}$ compr., piloso. Inflorescência tipo racemo, eixo primário reduzido $0,1 \mathrm{~mm}$ compr., eixo secundário $1 \mathrm{~mm}$ compr.; brácteas $2 \mathrm{~mm}$ compr., elíptico-lineares, margem pilosa; bractéolas $1 \mathrm{~mm}$ compr., rotundas, eixo central e margem pilosos; cálice glabro, lobos de comprimento igual, $2 \mathrm{~mm}$ compr., pilosos; hipanto $1 \mathrm{~mm}$ compr.; estames $5 \mathrm{~mm}$, disco estaminal piloso; estiletes 6-7 $\mathrm{mm}$ compr., base pilosa. Frutos $1 \times 1,5 \mathrm{~cm}$, subgloboides, cálice decíduo, glabros. Sementes $1-2,0,7 \times 0,8 \mathrm{~cm}$, globoide, maculada.

Material examinado: Mata de Piedade, 20.II.2009, fl., B.S. Amorim 390 et al. (UFP); 7.III.2009, fl., B.S. Amorim 397 et al. (UFP); Mata de Macacos, 14.III.2009, fl. e fr., B.S. Amorim 438 et al. (UFP).

Endêmica da Floresta Atlântica (Sobral et al. 2009), com ocorrência nas regiões Nordeste e Sudeste (Proença \& Sobral 2006; Sobral et al. 2010). Na USJ é uma espécie comum e encontrada no interior de fragmentos, ocupando o subdossel, em habitats de tabuleiro. Diferencia-se das demais espécies pela inflorescência com eixo primário reduzido, o hipanto prolongado acima do ovário e fruto subgloboide com cálice 4-mero decíduo. 
Psidium L., Sp. pl. 1: 470. 1753.

Arvoretas ou arbustos. Inflorescência tipo dicásio ou flores solitárias; botões florais fechados, abertura irregular; cálice (4)-5-mero, corola 5-mera; ovário 6-locular. Frutos globoides, lobos do cálice persistentes. Sementes reniformes, lisas, coloração uniforme.

Gênero amplamente distribuído na América Tropical e sub-tropical (Govaerts et al. 2010) com 100 espécies, 32 delas ocorrendo na Floresta Atlântica, sendo 12 endêmicas (Sobral et al. 2009).

\section{Psidium guajava L., Sp. pl. 1: 470. 1753.}

Fig. 3r

Arvoretas a arbustos 3-7 m alt., ramos jovens pilosos. Folhas 5-11,5 × 2,5-5,5 cm, cartáceas, elípticas, acuminadas, atenuadas, inteiras; venação primária sulcada adaxialmente, pilosa, secundária 10-15 pares, marginal a $1-2 \mathrm{~mm}$ da borda foliar; pecíolo 3-4 mm compr., piloso. Flores solitárias, brácteas lineares $3-4 \mathrm{~mm}$ compr., pilosas, pedúnculo ca. $2 \mathrm{~cm}$ compr., piloso; botão floral fechado, abertura irregular, cálice elíptico, constrição entre ovário e globo petalífero, piloso, lobos $0,6-0,8 \mathrm{~cm}$ compr., pilosos; hipanto alongado, $1 \mathrm{~mm}$ compr.; estame $6 \mathrm{~mm}$ compr., disco estaminal glabro; estilete $8 \mathrm{~mm}$ compr., glabro; ovário 6 a 8-locular. Frutos 3,5 $\times 3 \mathrm{~cm}$, subgloboides, glabros. Sementes numerosas, $0,3 \times 0,2 \mathrm{~cm}$, reniformes, coloração uniforme, lisas.

Material examinado: Mata de Piedade, 26.XII.2008, fr., B.S. Amorim 321 et al. (UFP); 11.III.2009, fl., B.S. Amorim 418 et al. (UFP).

Amplamente distribuída e cultivada na América Tropical e subtropical, introduzida em vários ambientes (Govaerts et al. 2010). Na USJ é uma espécie ocasional, encontrada na borda de fragmentos e em ambientes parcialmente antropizados. Diferencia-se de $P$. guineense $\mathrm{Sw}$. por apresentar venação secundária com 10-15 pares, as flores serem exclusivamente solitárias e os frutos maiores.

\section{Psidium guineense Sw., Prodr. 77. 1788.}

Fig. 3s-t

Arbustos 1-3 m alt., ramos jovens pilosos. Folha 7-11 ×4-7 cm, elíptica, apiculada a acuminada, obtusa; venação primária plana a saliente adaxialmente, glabra, secundária 6-8 pares, marginal a $1 \mathrm{~mm}$ da borda foliar; pecíolo $5 \mathrm{~mm}$ compr., piloso. Inflorescência tipo dicásio ou flores solitárias, eixo primário 1,3-3 cm compr., piloso, eixo secundário 1,3 cm compr., piloso, brácteas 4-5 mm compr., lineares, pilosas; botão floral fechado, abertura irregular, cálice elíptico, constrição entre ovário e globo petalífero, piloso, lobos 4-5,7 mm compr., pilosos; corola ca. 1,5 cm compr., pilosa adaxialmente; hipanto $1 \mathrm{~mm}$ compr.; estames 5$6 \mathrm{~mm}$ compr., glabros, disco estaminal glabro; estilete $11 \mathrm{~mm}$ compr., glabro; ovário 6-locular. Frutos $2 \times$ $2 \mathrm{~cm}$, globoides. Sementes numerosas, 0,2-0,3 $\times$ $0,1-0,2 \mathrm{~cm}$, reniformes, coloração uniforme, lisas.

Material examinado: Mata de Piedade, 11.III.2009, fl. e fr., B.S. Amorim 417 et al. (UFP); Mata de Vespas, 12.III.2009, fl. e fr., B.S. Amorim 421 et al. (UFP).

Amplamente distribuída e cultivada desde o México a Argentina (Govaerts et al. 2010). Na USJ é uma espécie comum e encontrada na borda de fragmentos. Diferencia-se de P. guajava L. por apresentar venação secundária com 6-8 pares, flores organizadas geralmente em dicásios simples ou múltiplos e frutos menores.

\section{Agradecimentos}

Ao Projeto "Sustentabilidade de remanescentes de Floresta Atlântica em Pernambuco e suas implicações para a conservação e desenvolvimento local" (CNPq-BMBF); à FACEPE, a bolsa concedida ao primeiro autor, aos curadores dos herbários visitados, à Regina Carvalho, ilustradora botânica e à equipe do Laboratório de Morfo-Taxonomia Vegetal.

\section{Referências}

Alves-Araújo, A.; Araújo, D.; Marques, J.; Melo, A.; Maciel, J.R.; Uirapuã, J.; Pontes, T.; Lucena, M.F.A.; Bocage, A.L.D \& Alves, M. 2008. Diversity of angiosperms in fragments of Atlantic Forest in the State of Pernambuco, northeastern Brazil. Bioremediation, Biodiversity and Bioavailability 2: 14-26.

Alves-Araújo, A. \& Alves, M. 2010. Flora da Usina São José, Igarassú, Pernambuco: Sapotaceae. Rodriguésia 61: 303-318.

Arantes, A.A. \& Monteiro, R. 2002. A família Myrtaceae na Estação Ecológica do Panga, Uberlândia, Minas Gerais, Brasil. Lundiana 3:111-127.

Barros, R.B. 2005. A família Myrtaceae na Reserva Biológica Guaribas, Paraíba, Brasil. Monografia de Graduação. Universidade Federal da Paraíba, João Pessoa. 65p.

Buril, M.T. \& Alves, M. 2011. Flora da Usina São José: Convolvulaceae. Rodriguésia 62: 93-105.

Govaerts, R.; Sobral, M.; Ashton, P; Barrie, F.; Holst, B.K.; Landrum, L.L.; Matsumoto, K.; Mazine, F.F.; Lughadha, E.N.; Proenca, C.; Soares-Silva, L.H.; Wilson, P.G. \& Lucas, E. 2010. World checklist of Myrtaceae. 
The Board of Trustees of the Royal Botanic Gardens, Kew. Disponível em <http://www.kew.org/wcsp/>. Acesso em 29 Jul 2010.

Hickey, L.J. 1973. Classification of architecture of dicotyledonous leaves. American Journal of Botany 60: 17-33.

Landrum, L.R. 1986. Campomanesia, Pimenta, Blepharocalyx,Legrandia, Acca, Myrrhinium, and Luma (Myrtaceae). Flora Neotropica 45: 1-179.

Legrand, C.D. \& Klein, R.M. 1967-1978. Mirtáceas. In: Reitz, P.R. Flora Ilustrada Catarinense. Itajaí. Santa Catarina. Pp 1-876.

Lourenço, A.R. 2010. A família Myrtaceae no limite norte de distribuição da Mata Atlântica. Dissertação de Mestrado. Universidade Federal de Pernambuco. 111p.

McVaugh, R. 1956. Tropical American Myrtaceae, notes on generic concepts and descriptions of previously unrecognized species. Fieldiana 29: 145-228.

McVaugh, R. 1968. The genera of american Myrtaceae, an interim report. Taxon 7: 354-418.

McVaugh, R. 1969. The botany of Guayana Highland: VIII. Myrtaceae. Memoirs of the New York Botanical Garden 18: 55-286.

Melo, A.; Alves-Araújo, A. \& Alves, M. 2010 Flora da Usina São José, Igarassú, Pernambuco: Burmaniaceae e Gentianaceae. Rodriguésia 61: 431-440.

Mori, S.A.; Mattos-Silva, L.A.; Lisboa, G. \& Coradin, L. 1985. Manual de manejo do herbário fanerogâmico. Centro de Pesquisas do Cacau, Ilhéus. 97p.

Pontes, T. \& Alves, M. 2010. Flora da Usina São José, Igarassú, Pernambuco: Araceae. Rodriguésia 61: 689-704.

Proença, C.E.B. \& Sobral, M. 2006. Myrtaceae In: Barbosa, M.R.V.; Sothers, C.; Mayo, S.; GamarraRojas, C.F.L. \& Mesquita, A.C. Checklist das plantas do nordeste brasileiro: angiospermas e gymnospermas. Ministério de Ciência e Tecnologia, Brasília. Pp. 111-113

Romagnolo, M.B. \& Souza, M.C. 2006. O Gênero Eugenia L. (Myrtaceae) na planície alagável do rio Paraná, estados de Mato Grosso do Sul e Paraná, Brasil. Acta Botanica Brasilica 20: 529-548.

Silva, A.G.; Sá-e-Silva, I.M.M.; Rodal, M.J.N. \& Linse-Silva, A.C.B. 2008. Influence of edge and topography on canopy and sub-canopy structure of an Atlantic Forest fragment in Igarassu, Pernambuco State, Brazil. Bioremediation, Biodiversity and Bioavailability. 2: 41-46.

Silva, J.O.N. 2009. A família Myrtaceae no Parque Estadual das Dunas do Natal - RN, Brasil. Dissertação de Mestrado. Universidade Federal do Rio Grande do Norte. 59p.

Sobral, M. 1993. Sinopse de Myrciaria (Myrtaceae). Napaea 9: 13-41.
Sobral, M. 2003. A família Myrtaceae no Rio Grande do Sul. Ed. Unisinos. 215p.

Sobral, M. 2006. Três novas Myrtaceae de Santa Teresa, Espírito Santo, Brasil. Boletim do Museu de Biologia Melo Leitão 20: 73-82.

Sobral, M.; Lucas, E.; Landrum, L.; Soares-Silva, L. 2009. Myrtaceae. In: Stheman, J.; R. Forzza, R.C.; Salino, A.; Sobral, M.; Costa, D.P.; Kamino, L.H.Y. Plantas da Floresta Atlântica. Rio de Janeiro. Pp. 352-366.

Sobral, M.; Proença, C.; Souza, M.; Mazine, F. \& Lucas, E. 2010. Myrtaceae. In: Forzza, R.C.; Leitman, P.M.; Costa, A.F.; Carvalho Jr., A.A.; Peixoto, A.L.; Walter, B.M.T.; Bicudo, C.; Zappi, D.; Costa, D.P.; Lleras, E.; Martinelli, G.; Lima, H.C.; Prado, J.; Stehmann, J.R.; Baumgratz, J.F.A.; Pirani, J.R.; Sylvestre, L.; Maia, L.C.; Lohmann, L.G.; Queiroz, L.P.; Silveira, M.; Coelho, M.N.; Mamede, M.C.; Bastos, M.N.C.; Morim, M.P.; Barbosa, M.R.; Menezes, M.; Hopkins, M.; Secco, R.; Cavalcanti, T.B.; Souza, V.C. Lista de espécies da flora do Brasil. Jardim Botânico do Rio de Janeiro. Disponível em <http://floradobrasil.jbrj.gov.br/2010/FB010791>. Acesso em 25 Jul 2010.

Souza, M.C.; Morim, M.P; Conde, M.M.S. \& Menezes, L.F.T. 2007. Subtribo Myrciinae O. Berg (Myrtaceae) na restinga da Marambaia, RJ, Brasil. Acta Botanica Brasilica 21: 49-63.

Souza, M.C. \& Morim, M.P. 2008. Subtribos Eugeniinae O. Berg e Myrtinae O. Berg (Myrtaceae) na restinga da Marambaia, RJ, Brasil. Acta Botânica Brasílica 22: 652-683.

Spjut, R.W. 1994. A Systematic treatment of fruit types. Memoirs of The New York Botanical Garden 70: 1-182.

Stehmann, J.; R. Forzza, R.C.; Sobral, M. \& Kamino, L.H.Y. 2009. Gimnospermas e Angiospermas In: Stheman, J.; R. Forzza, R.C.; Salino, A.; Sobral, M.; Costa, D.P. \& Kamino, L.H.Y. Plantas da Floreta Atlântica. Rio de Janeiro. Pp. 27- 37.

Thiers, B. 2010. [continuously updated]. Index Herbariorum: A global directory of public herbaria and associated staff. New York Botanical Garden's Virtual Herbarium. Disponível em <http:// sweetgum.nybg.org/ih/>. Acesso em 19 Jul 2010.

Trindade, M.B.; Lins-e-Silva, A.C.B.; Silva, H.P.; Figueira, S.B. \& Schessl, M. 2008. Fragmentation of the Atlantic rainforest in the northern coastal region in Pernambuco, Brazil: recent changes and implications for conservation. Bioremediation, Biodiversity and Bioavailability 2: 5-13.

Wilson, P.G.; O'Brien, M.M., Gadek, P.A. \& Quinn, C.J. 2001 Myrtaceae revised: a reassessment of intrafamilial groups. American Journal of Botany 88: 2012-2025. 


\section{Lista de Exsicatas}

Albuquerque, N.A. 421 (9), 538 (22), 581 (1). Allen, P.H. s/n MO 1189024 (19). Almeida, J. 1268 (10). Alves-Araújo, A. 233 (17), 262 (2), 281 (23), 627 (14), 764 (19), 819 (1), 875 (11), 877 (2), 906 (9), 1076 (17), 1167 (11). Amorim, B.S. 318 (18), 320 (12), 321 (22), 387 (2), 388 (17), 389a (1), 389b (6), 390 (21), 397 (21), 404 (17), 406 (2), 407 (13), 408 (18), 411 (14), 417 (23), 418 (22), 419 (19), 421 (23), 423 (9), 424 (11), 426 (10), 428 (14), 430 (1), 432 (14), 433 (13), 435 (17), 436 (18), 438 (21), 439 (19), 440 (14), 442 (19), 443 (14), 444 (3), 445 (14); 447 (6), 449b (2), 450 (1), 452 (14), 453 (18); 454 (15), 479 (13), 481 (7), 520 (15), 524 (9), 525 (7), 528 (9), 529 (7), 533 (18), 553 (16), 555 (18), 556 (19), 558 (1), 559 (6), 562 (15), 565 (2), 592 (16), 598 (19), 626 (14), 645 (7), 648 (2), 691 (8), 764 (5). Araújo, D. 152 (14), 539 (10), 621 (9). Bezerra, G.J. 184 (2). Cavancanti, D. 32 (15), 149 (2). Ducke s/n IPA 14860 (4). Falcão, M. 76 (1). Ferreira, V. 1 (12). Garcia, J.D. 1173 (1). Gardner, G. 1294 (2), 1625 (14). Guerra, T.N.F. 120 (10), 172 (7). Hassler, E. 6999 (9). Hostm \& Kappl s/n MO 2527443 (6). Irapuã, J. 12 (11). Lima, A. 60-68 (5), 65-4346 (1). Lins e Silva, A.C.B. 284 (1), 311 (9), 337 (2), 345 (11), 355 (20). Lucena, M.F.A. 954 (11) Luschnath, B. s.n. 4776 NY (13). King, G. 2622 (17). Marques, J.S. 124 (1), 231 (4), 262 (11), 298 (2). Martius s/n, M 19934 (3). Melo, A. 29 (18), 32 (14), 54 (21), 228 (23), 238 (3), 345 (21). Mendes, P.G.A. 68 (1). Moraes, M. 21 (1). Nascimento, L.M. 656 (6), 681 (13), 702 (2), 718 (13). Oliveira, A. 7 (4). Oliveira, N. 568 (6). Pessoa, E. 24 (6), 47 (23), 108 (6). Pontes, T.A. 78 (1), 80 (14). Riedel s/n 276538 K (11), 202 (15), 2563 (23). Sá e Silva, I.M.M. 215 (4), 314 (22), 330 (13). Salgado, R. s/n IPA 55204 (12). Sellow 782 (12). Silva, H.C.H. 396 (1). Silva, M.A.M. 11 (1), 38 (11). Siqueira, D.R. 120 (20). Sobrinho, M.S. 555 (3), 557 (7), 566 (3). Souza, J.A.N. 312 (18), 417 (10), 470 (15), 478 (15), 582 (4), 591 (4), 630 (16). Spruce, R. 1842 (18). 